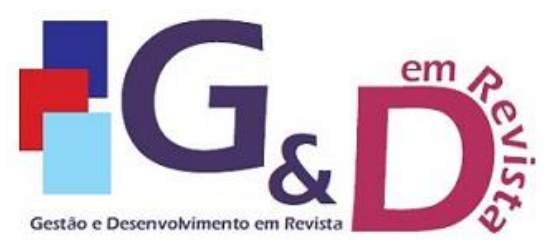

Gestão e Desenvolvimento em Revista V. 6, N. 1, jan-jun/2020, p. 28-45.

ISSN online: $2446-8738$

Artigo recebido em: $26 / 03 / 2020$

Artigo aprovado em: 10/06/2020

\title{
SATISFAÇÃO NO TRABALHO E SAÚDE ORGANIZACIONAL: O ÇASO DE UMA ORGANIZAÇÃO INDUSTRIAL
}

\author{
Adilson Carlos da Rocha \\ Graduação, Mestrado e Doutorado em Administração. Atualmente é professor na Universidade \\ Estadual do Oeste do Paraná - Unioeste. \\ E-mail: adilson.rocha@unioeste.br \\ Bruna Chicoski Silveira \\ Graduação em Administração pela Universidade Estadual do Oeste do Paraná - Unioeste. \\ E-mail: bruna_c_silveira@hotmail.com
}

\begin{abstract}
Resumo
O presente estudo teve como objetivo analisar a satisfação no trabalho e a saúde organizacional de acordo com a percepção dos colaboradores de uma indústria de pias localizada na cidade de Ampére - PR. A abordagem utilizada para o estudo foi quantitativa, com características de pesquisa descritiva. A técnica utilizada para coleta de dados foi o survey. A amostra foi composta por 93 colaboradores, os quais participaram do estudo, o que correspondeu a 64\% da população estimada. Os instrumentos de pesquisa utilizados foram escalas psicométricas validadas como EST, elaborada por Siqueira (2008) e EPSaO elaborada por Gomide Júnior e Fernandes (2008). Considerando os resultados, a partir das dimensões da EST verificou-se que em todas as dimensões: satisfação com os colegas, satisfação com o salário, satisfação com a chefia, satisfação com a natureza do trabalho e satisfação com promoções os resultados sugerem grau de satisfação com o trabalho, a partir da percepção dos colaboradores da organização. Diante dos resultados, a partir das escalas utilizadas (EST e EPSaO) as evidências sugerem que a organização objeto deste estudo apresenta graus de satisfação no trabalho e de saúde organizacional satisfatórios de acordo com a opinião dos seus colaboradores.
\end{abstract}

Palavras-Chave: Satisfação no Trabalho. Saúde Organizacional. Indústria de Pias.

\begin{abstract}
This study aimed to analyze job satisfaction and organizational health according to the perception of employees of a sink industry located in the city of Ampére - PR. The approach used for the study was quantitative, with descriptive research characteristics. The technique used for data collection was the survey. The sample consisted of 93 employees, who participated in the study, which corresponded to $64 \%$ of the estimated population. The research instruments used were psychometric scales validated as EST, developed by Siqueira (2008) and EPSaO elaborated by Gomide Júnior and Fernandes (2008). Considering the results, from the EST dimensions it was found that in all dimensions: satisfaction with colleagues, satisfaction with salary, satisfaction with management, satisfaction with the nature of work and satisfaction with promotions, the results suggest a degree of satisfaction with work, from the perception of the organization's employees. In view of the results, based on the scales used (EST and EPSaO), the evidence suggests that the organization object of this study has satisfactory degrees of job satisfaction and organizational health according to the opinion of its employees.
\end{abstract}

Key words: Job Satisfaction. Organizational Health. Sinks Industry. 


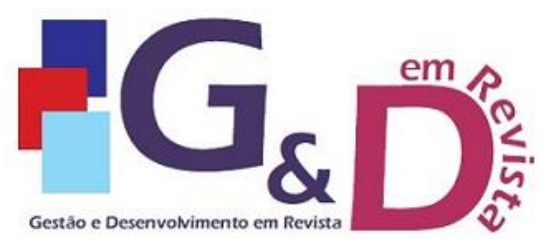

Gestão e Desenvolvimento em Revista V. 6, N. 1, jan-jun/2020, p. 28-45.

ISSN online: $2446-8738$

Artigo recebido em: $26 / 03 / 2020$

Artigo aprovado em: 10/06/2020

\section{INTRODUÇÃO}

Atualmente é cada vez mais frequente visualizar organizações que se preocupam com seus colaboradores e com a infraestrutura que ela oferece aos mesmos para que eles possam desenvolver bem suas funções e atividades. As mudanças tecnológicas, sociais, culturais, políticas, demográficas que ocorrem contribuem para que as organizações voltem seu olhar para os trabalhadores.

As organizações são formadas por pessoas e o seu bom ou mal desempenho depende delas, visto que, uma organização espera que os colaboradores trabalhem em prol da mesma para que os objetivos sejam alcançados. Por este motivo, a gestão de pessoas surgiu para ter um olhar voltado para esse lado mais humano em relação as pessoas, tendo uma maior preocupação com o ser humano em seu ambiente de trabalho. A melhoria promovida pelas organizações permite que os trabalhadores se sintam satisfeitos e possam trabalhar com o coração e inteligência e não apenas por obrigação.

A forma como as organizações desenvolvem suas atividades gera um reflexo na satisfação dos trabalhadores. A satisfação no trabalho caracteriza-se como a atitude geral de uma pessoa em reação ao trabalho que desempenha, e o bom desempenho deste trabalho pode estar diretamente envolvido com infraestrutura disponível, com o convívio dos colegas e superiores, com as políticas organizacionais, obediência a regras, entre outros motivos. A satisfação no trabalho é um fator que pode ter grande predominância nos indicativos de produtividade das organizações. Desta forma, é importante identificar os níveis de satisfação dos trabalhadores de uma organização para aumentar as possibilidades de sucesso da mesma.

Outro fator que tem grande relevância para o desenvolvimento de uma organização é o grau de saúde organizacional ofertada pelas organizações. A adaptação das organizações traz grandes desafios, pois é necessário ter um equilibrio entre as necessidades das organizações e dos trabalhadores. Segundo Gomide Jr. et al. (2008), saúde organizacional diz respeito a capacidade da organização de desenvolver altos níveis de adaptabilidade e flexibilidade as demandas externas quando necessário, e ainda de promover alto grau de integração entre os colaboradores e suas equipes de trabalho.

Considerando a importância destes temas, este estudo de pesquisa tem como questão norteadora: Como é percebida a satisfação no trabalho e a saúde organizacional, a partir da percepção dos trabalhadores em uma organização industrial? Para buscar respostas a esta questão este estudo teve como objetivo analisar as relações e o grau de satisfação no trabalho e saúde organizacional a partir da percepção dos colaboradores em uma indústria de pias localizada na região sudoeste do Paraná.

\section{SATISFAÇÃO NO AMBIENTE DE TRABALHO E SAÚDE ORGANIZACIONAL}

O ambiente organizacional é marcado por grandes transformações, no início a meta era alta produtividade e maior ganho de capital financeiro, já como passar do tempo, a preocupação passou a ser mais com os indivíduos, o trabalhador e sua satisfação com as atividades desempenhadas.

Satisfação no trabalho é um tema que vem mobilizado pesquisadores no campo do comportamento organizacional e de gestores organizacionais desde as 
primeiras décadas do século XX. Inicialmente a compreensão dos sentimentos que emergiam entre os trabalhadores foi marcada pela aproximação de satisfação com o processo motivacional. Pesquisadores defendiam a noção de ser a satisfação no trabalho, um componente da motivação que levava trabalhadores a obterem indicadores de comportamentos de trabalho importantes para os interesses empresarias. Portanto, inicialmente satisfação foi estudada como uma causa de comportamentos no trabalho (SIQUEIRA, 2008).

Com o tempo, o tema satisfação no trabalho tem crescido em importância no âmbito dos estudos organizacionais, várias são as abordagens de pesquisas, expondo o quanto é necessário para uma gestão eficaz e inteligente compreender e avaliar as condições de trabalho. A satisfação do indivíduo com o trabalho é altamente positiva, tanto para a pessoa como para a organização (FREIRE, 1999).

Para McShane e Von Glinow (2013), satisfação no trabalho trata-se de uma apreciação das características percebidas no trabalho, do respectivo ambiente e das experiências emocionais nele vividas. Os trabalhadores que se sentem satisfeitos tem avaliações favoráveis de seus empregos. A satisfação no trabalho pode ser melhor visualizada como uma coleção de atitudes a respeito de diferentes aspectos do contexto de emprego e trabalho.

Satisfação no trabalho também é entendida como um conjunto de sentimentos e emoções favoráveis ou desfavoráveis por meio dos quais os trabalhadores veem seu trabalho. A satisfação no trabalho é um sentimento de afeição ou rejeição relativa no tocante a algo (NEWSTROM, 2008). Martinez e Paraguay (2003), destacam que satisfação é um fenômeno de difícil definição, pois é um estado subjetivo, que varia de pessoa para pessoa, uma vez que diferentes pessoas perante situações idênticas reagem e valorizam aspectos diferentes.

McShane e Von Glinow (2013), apontam que o trabalhador pode gostar de seus colegas de trabalho, mas pode estar menos satisfeito com a sua carga de trabalho. Segundo os autores saber o quanto os trabalhadores estão satisfeitos no trabalho depende das pessoas e do ambiente. O simples fato de uma pessoa estar satisfeita, não significa que existe obrigatoriamente um comportamento ativo marcado pela procura de um melhor rendimento no trabalho. Pode existir um colaborador que esteja satisfeito, mas que não tenha atração por aquilo que lhe é exigido que faça (SILVA, 1998).

Para Freire (1999), satisfação no trabalho é um conceito que evolve aspectos emocionais positivos e negativos, caracterizando uma atitude do indivíduo em relação ao seu trabalho. O comportamento, então, é determinado pela interação de fatores internos como motivação e fatores externos decorrentes de características organizacionais, como condições ambientais e físicas. Desta forma o comportamento que o indivíduo apresenta na organização não é função apenas das características de seu sistema individual, mas também resultado dos problemas e desafios que ele percebe no ambiente organizacional (FREIRE, 1999).

Estudos longitudinais, constataram que o nível de satisfação geral no trabalho tem siso historicamente alto e estável. Embora, as expectativas dos trabalhadores tenham, ao longo do tempo, aumentado e mudado de foco, a qualidade das práticas administrativas também foi aperfeiçoada (NEWSTROM, 2008).

Nesses estudos uma constante preocupação dos pesquisadores recai sobre a construção e validação de medidas de satisfação no trabalho. Por ser um tema que é de relevante interesse não somente para pesquisadores, mas também para os 
gestores das organizações, as análises dos índices de satisfação no trabalho passaram a ser constantes em diversas organizações. Para constituir uma medida útil de satisfação no trabalho é indispensável que ela permita avaliar aspectos que a teoria aponta como dimensões do conceito de satisfação (SIQUEIRA, 2008).

A administração segundo Newstrom (2008), necessita de informações sobre a satisfação dos empregados no trabalho para tomar decisões sólidas, tanto na prevenção quanto na resolução de problemas dos trabalhadores. Os estudos sobre satisfação podem produzir inúmeros benefícios tanto no contexto geral quanto no específico de cada organização.

O conceito de saúde organizacional gera várias divergências entre diversos autores e pode ser encontrado com vários significados, sendo o mais comum a vinculação da saúde organizacional com saúde do indivíduo (HERNANDEZ, 2007).

As primeiras proposições sobre saúde organizacional surgiram na década de 1950, onde a sua definição teve raízes no conceito de efetividade organizacional. Aquelas organizações que apresentassem maior adaptabilidade, testes da realidade e também 0 senso de identidade seria a organização saudável, pois a adaptabilidade refere-se a uma característica que acaba coincidindo com a capacidade de resolver problemas, que depende da flexibilidade organizacional. Já o teste de realidade indica para a habilidade organizacional em receber, conhecer e interpretar de forma correta as condições do meio ambiente que são relevantes para o funcionamento da organização. O senso de identidade está relacionado com 0 conhecimento que a organização tem sobre o que ela é, quais suas metas, e o que deve fazer. A efetividade organizacional foi definida como a extensão em que uma organização alcança seus objetivos sem incapacitar os meios e recursos e sem gerar tensão entre seus membros (GOMIDE JÚNIOR; FERNANDES, 2008).

O primeiro teórico a conceituar saúde organizacional foi Bennis (1962), o qual tomou como base o conceito de efetividade organizacional unindo ao fato de considerar as organizações como um organismo vivo, utilizando os critérios de saúde mental para definir o conceito de saúde organizacional. A junção dos critérios foi justificada por considerar que os mesmos critérios utilizados para determinar a saúde individual poderiam ser adotados para definir a saúde das organizações. As organizações têm como maior desafio atender as condições de mudanças e de adaptar-se a tensão externa (SCHEIN, 1965).

Outra definição para efetividade foi proposta por Katz e Kahn (1966), o qual contemplou critérios internos e externos às organizações. Efetividade para os autores foi definida como a maximização dos rendimentos organizacionais determinada por uma combinação de eficiência das organizações, como um sistema, e seu êxito em obter os insumos necessários em condições vantajosas. Uma organização efetiva seria aquela capaz de gerar e aumentar os lucros em curto prazos e mantê-los por um período mais longo, levando ao seu crescimento e sobrevivência, mantendo neste processo o equilíbrio entre os componentes internos e externos.

Fordyce e Weil (1971), compartilhavam de uma linha de pensamento o qual sugere que uma organização saudável demostra as mesmas qualidades de um ser humano saudável, ou seja, que é independente, otimista, sensível e adaptável a mudanças e que não se surpreende facilmente. Os sinais de que uma organização é saudável estão no compartilhamento dos objetivos da organização, na existência de um ambiente onde as pessoas se sintam à vontade para falar sobre problemas diretamente com os responsáveis, na ênfase em resoluções práticas aos problemas, 
na determinação de que as decisões são tomadas segundo a competência, a responsabilidade e a organização do trabalho e não segundo a o nível hierárquico.

Também é sinal de uma organização saudável a concordância de que alguns conflitos são necessários para o processo decisório e para 0 desenvolvimento pessoal, o entendimento de que o risco é necessário para 0 crescimento da organização, o sentimento de que se aprende com os erros, a busca para adequar procedimentos e políticas de forma que auxiliem a realização das tarefas, o clima de inovação e facilidade de adaptação da organização as demandas internas e externas.

Saúde organizacional é conceituada por Jaffe (1995) como sendo uma visão estendida de efetividade, e afirma que a organização necessita ser saudável em vários níveis: (i) para seus colaboradores, proporcionando a eles um local de trabalho estável; (ii) para seus acionistas, oferendo ganhos nos valores das ações; (iii) para seus fornecedores e clientes, oferecendo bons serviços e valores; (iv) para comunidade em que está inserida por meio da responsabilidade econômica social.

Diversos autores conceituam saúde organizacional como sendo uma derivação dos conceitos de efetividade. Para as organizações modernas é fundamental que haja um bom nível de interação e motivação entre os trabalhadores, para que eles se sintam engajados com o que a empresa almeja. Trata- se de alinhar e motivar os colaboradores em torno da visão da organização. Quando a organização conseguir que os trabalhadores se tornem envolvidos com os seus objetivos, a mesma poderá ser capaz de reagir aos fatores externos (BEZERRA, 2017).

Devido aos vários pensamentos sobre o tema, foi criada e validada a Escala de Percepção da Saúde Organizacional, com o propósito de verificar a percepção dos colaboradores a respeito da saúde da organização em que estão inseridos e tem embasamento nos critérios de saúde organizacional levantados por Bennis (1962), Schein (1965) e Fordyce e Well (1971) e baseados na primeira proposição de validação de Gomide Jr. et al. (1999) (BEZERRA, 2017).

Para construção do instrumento foi identificado dois fatores, sendo (i) Integração de Pessoas e Equipes, que refere-se as crenças do trabalhador de que a organização é capaz de incentivar o compartilhamento dos objetivos organizacionais e a integração de seus membros as suas equipes de trabalho e (ii) Flexibilidade e Adaptabilidade a Demandas Externas, que refere-se as crenças do trabalhador de que a organização possui políticas e procedimentos de trabalho flexíveis e voltados para a adaptação da organização as demandas do ambiente externo (GOMIDE JR; FERNANDES, 2008).

\section{PROCEDIMENTOS METODOLOGICOS}

O presente estudo é de abordagem quantitativa, pois emprega-se métodos estatísticos. Na abordagem quantitativa, coletam-se e quantificam-se dados e opiniões mediante o emprego de recursos e técnicas estatísticas, partindo das mais simples, como porcentagem, média e desvio padrão, até aquelas mais complexas, como coeficiente de correlação, análise de regressão (GONÇALVES, 2005). Pesquisas quantitativas supõe a delimitação clara dos objetivos da investigação, a definição da população, das variáveis a serem investigadas, do método de coleta de dados e das técnicas, tanto da extração da amostra, como da aplicação do instrumento e da codificação dos dados (CHIZZOTTI, 1995). 
Em relação aos fins, a pesquisa é classificada como descritiva, pois os objetivos desse tipo de pesquisa vêm ao encontro dos objetivos específicos do presente trabalho. De acordo com Vergara (2014), a pesquisa descritiva expõe características de uma determinada população ou fenômeno, e também pode estabelecer correlações entre variáveis e definir sua natureza.

\subsection{TÉCNICAS DE COLETA E ANÁLISE DOS DADOS}

A estratégia de coleta utilizada foi o survey, o qual é um procedimento para coleta de dados primários a partir de indivíduos. Esta estratégia de coleta é usada quando o projeto de pesquisa envolve a coleta de informações de uma grande amostra de indivíduos. Os métodos de coleta de dados de survey recaem em duas categorias amplas: administração de questionários para que o próprio respondente responda e entrevista (HAIR JR et al., 2005). Os instrumentos de coleta foram aplicados junto aos 145 colaboradores da organização estudada, dos quais 93 devolveram o questionário respondido. A aplicação aconteceu no período de 15 de julho a 30 de agosto de 2019, onde todos foram convidados a participar do estudo.

A estratégia utilizada para a coleta dos dados foi o survey cross-sectional. De acordo com Malhotra (2012), o survey cross-sectional apresenta algumas vantagens como: (i) apresenta flexibilidade na obtenção de dados junto à fonte de pesquisa; (ii) permite ao pesquisador focar um estrato da população de interesse; (iii) possibilita, no processo de análise dos dados, manipular de diversas formas, identificando as diferenças entre grupos bem como o relacionamento entre variáveis.

Como instrumentos de coleta de dados desta pesquisa foi utilizada a Escala de Satisfação no Trabalho - EST apresentada por Siqueira (2008) a qual teve como objetivo identificar o grau de satisfação dos trabalhadores da organização objeto de estudo. As dimensões que compõem a EST apresentam-se no Quadro 1.

QUADRO 1 - DIMENSÕES, DEFINIÇÕES, ITENS DA EST

\begin{tabular}{|l|l|l|}
\hline Dimensões & Definições & Itens \\
\hline $\begin{array}{l}\text { Satisfação com os } \\
\text { colegas }\end{array}$ & $\begin{array}{l}\text { Contentamento com a colaboração, a amizade, a confiança e o } \\
\text { relacionamento mantido com os colegas. }\end{array}$ & $\begin{array}{l}1,6,14,17 \\
\text { e } 24\end{array}$ \\
\hline $\begin{array}{l}\text { Satisfação com o } \\
\text { salário }\end{array}$ & $\begin{array}{l}\text { Contentamento com o que recebe como salário se comparado com } \\
\text { o quanto o indivíduo trabalha, com sua capacidade profissional, } \\
\text { com o custo de vida e com os esforços feitas na realização do } \\
\text { trabalho. }\end{array}$ & $\begin{array}{l}5, \quad 8, \quad 12, \\
15 \text { e } 21\end{array}$ \\
\hline $\begin{array}{l}\text { Satisfação com a } \\
\text { chefia }\end{array}$ & $\begin{array}{l}\text { Contentamento com a organização e capacidade profissional do } \\
\text { chefe, com o seu interesse pelo trabalho dos subordinados e e } \\
\text { entendimento entre eles. }\end{array}$ & $\begin{array}{l}2,9,19,22 \\
\text { e 25 }\end{array}$ \\
\hline $\begin{array}{l}\text { Satisfação com a } \\
\text { natureza } \\
\text { trabalho }\end{array}$ & $\begin{array}{l}\text { Contentamento com o interesse despertado pelas tarefas, com a a } \\
\text { capacidade de elas absorverem o trabalhador e com a variedade } \\
\text { das mesmas. }\end{array}$ & $\begin{array}{l}7,11,13, \\
18 \text { e } 23\end{array}$ \\
\hline $\begin{array}{l}\text { Satisfação com as } \\
\text { promoções }\end{array}$ & $\begin{array}{l}\text { Contentamento com o número de vezes que já recebeu } \\
\text { promoções, com as garantias oferecidas a quem é promovido, com } \\
\text { a maneira de a empresa realizar promoções e com o tempo de } \\
\text { espera pela promoção }\end{array}$ & $\begin{array}{l}3,4,10, \\
16 \text { e 20 }\end{array}$ \\
\hline
\end{tabular}

Fonte: Adaptado de Siqueira (2008).

Para avaliar a percepção de saúde organizacional, foi utilizada a Escala de Saúde Organizacional - EPSaO apresentada por Gomide Jr e Fernandes (2008). Os fatores e as variáveis que compõem o construto saúde organizacional estão apresentados no Quadro 2. 
QUADRO 2 - DENOMINAÇÃO, DEFINIÇÕES, ITENS DA EPSaO

\begin{tabular}{|c|c|c|}
\hline Fatores & Variáveis & Itens \\
\hline $\begin{array}{l}\text { Integração de } \\
\text { pessoas e equipes }\end{array}$ & $\begin{array}{l}\text { Crenças do empregado de que organização é capaz de } \\
\text { estimular compartilhamento dos objetivos organizacionais } \\
\text { a integração de seus membros as suas equipes de } \\
\text { trabalho. }\end{array}$ & $\begin{array}{l}1,2,3,4,5,6 \\
7,8,9,10,11, \\
12,13,14,15, \\
17,18,19,20 \\
21\end{array}$ \\
\hline $\begin{array}{l}\text { Flexibilidade e } \\
\text { adaptação demanda } \\
\text { externas }\end{array}$ & $\begin{array}{l}\text { Crenças do empregado de que a organização possui } \\
\text { políticas e procedimentos de trabalho flexíveis e voltados } \\
\text { para a adaptação da organização às demandas do } \\
\text { ambiente externo. }\end{array}$ & $\begin{array}{l}16,22,23,24, \\
25,26,27\end{array}$ \\
\hline
\end{tabular}

Fonte: Adaptado de Gomide Jr. e Fernandes (2008).

Para a análise dos dados coletados foram aplicadas técnicas de estatística descritiva, as quais segundo Martins e Theóphilo (2009), tem como objetivo a organização, sumarização e descrição de um conjunto de dados, através da construção de gráficos, tabelas, e do cálculo de medidas a partir de uma coleção de dados numéricos. A análise e interpretação foi orientada a partir da aplicação das técnicas associadas a estatística descritiva.

Para análise e interpretação da EST foi computado cinco escores médios. O cálculo de cada escore foi obtido somando os valores assinalados pelos respondentes em cada um dos itens que integra cada dimensão e, a seguir dividiuse esse valor pelo número de itens da dimensão. Desta forma, foi considerado que quanto maior foi o valor do escore médio, maior é o grau de contentamento ou satisfação do empregado com aquela dimensão do seu trabalho. Assim, valores entre 5 e 7 tendem a indicar satisfação. Por outro lado, valores entre 1 e 3,9 tendem a sinalizar insatisfação, enquanto valores entre 4 e 4,9 informam um estado de indiferença (SIQUEIRA, 2008).

Para análise dos dados coletados pela EPSaO, foi efetuado o cálculo do escore médio somando-se os valores assinalados pelos respondentes em cada um dos itens que integra cada fator e dividindo-se este valor pelo número de itens. $\mathrm{Na}$ interpretação dos resultados deve considerar que quanto maior o valor do escore fatorial médio, maior é a percepção do respondente de que sua organização empregadora apresenta a característica contemplada naquele fator. Assim, médias fatoriais entre 1 e 2,9 tendem a indicar que o empregado não percebe a característica enunciada pelo fator, médias entre 4 e 5 tendem a indicar que o empregado percebe a característica enunciada, enquanto médias entre 3 e 3,9 tendem a indicar uma dúvida do respondente quanto à presença daquela característica enunciada pelo fator (GOMIDE JR; FERNANDES, 2008).

\section{APRESENTAÇÃO E ANÁLISE DOS DADOS}

\subsection{CARACTERIZAÇÃO DA ORGANIZAÇÃO}

O sonho em comum de dois amigos de abrir sua própria empresa fez com que surgisse em 15 de julho de 1990 na cidade de Ampére região sul do Paraná uma indústria de pias. A pequena indústria que na época produzia apenas pias de 
aço inox e alumínio, a qual era pequena em seu porte, mas forte e determinada a vencer as dificuldades que viessem a surgir, através da coragem e entusiasmos dos fundadores que acreditaram no potencial de seu negócio, fez com que a empresa se tornasse atualmente uma das maiores fabricantes de pias do Brasil.

A empresa tem sua matriz situada na cidade de Ampére-PR, e nesses 29 anos de trajetória esteve sempre em constantes investimentos, em 2003 investiu em uma nova unidade fabril no estado de Pernambuco na cidade de Escada, visando atender o mercado da região nordeste. Conta também, com um centro de distribuição no estado de São Paulo, na cidade de Atibaia. A organização conta com frota própria de caminhões, garantindo assim agilidade e eficiência na entrega de seus produtos.

Visando atender todos os tipos de públicos e buscando expandir seu mercado a empresa em estudo adquiriu em 2003 a marca Debacco, a qual no ano de 2019 completa 50 anos de existência. Seus produtos são direcionados para um público mais exigente e que busca um maior requinte, design e inovação nos acabamentos.

\subsection{CARACTERIZAÇÃO DOS PARTICIPANTES DO ESTUDO}

A amostra deste estudo foi composta por 93 indivíduos pesquisados no seu ambiente de trabalho, o que correspondeu a $64 \%$ da população estimada. De acordo com os dados, verifica-se que a maioria dos respondentes é do gênero masculino, onde representa $87,1 \%$ dos colaborados, enquanto as mulheres representam $12,9 \%$ do total.

Quanto ao setor em que os respondentes trabalham, verifica-se que 59,1\% trabalha no setor produtivo da organização, 16,1\% ocupam cargos na área administrativa, o setor de manutenção apresenta 5,4\% e a gerência possui a mesma representatividade com $5,4 \%$ dos respondentes.

Em relação a escolaridade grande parte dos entrevistados 50,5\% declarou ter concluído o ensino médio, $18,3 \%$ possuem apenas o ensino fundamental, uma parte possui graduação sendo completa ou incompleta com 15,1\% e 5,4\%, respectivamente completando a totalidade da porcentagem de escolaridade, tem-se a pós-graduação com $8,6 \%$ e outros com $2,2 \%$.

A pesquisa também buscou verificar o estado civil dos respondentes, onde identificou-se que maior parte dos indivíduos 53,8 \% são casados, 29,0\% pertence ao estado civil solteiro, $12,9 \%$ indicaram pertencer a outro estado civil e $4,3 \%$ são divorciados.

No que diz respeito ao tempo de serviço na empresa, constatou-se uma média de 7,3 anos, sendo o mínimo de 1 ano e o máximo 25 anos de trabalho na organização. Já em relação a faixa etária, constatou-se uma média de 33,5 anos, o qual teve respondentes com a idade mínima de 16 anos e a máxima de 64 anos.

\subsection{RESULTADOS A PARTIR DA EST E EPSAO}

\subsubsection{Comportamento das variáveis utilizadas pela EST e EPSaO}

A confiabilidade significa que a escala deve consistentemente refletir o construto que está medindo. Em termos estatísticos, o modo padrão para analisar a 
confiabilidade é baseada no conceito de que itens individuais devem produzir resultados consistentes em todo o questionário (FIELD, 2009).

Os instrumentos utilizados na pesquisa - Escala de Satisfação no Trabalho (EST) e Escala de Percepção de Saúde Organizacional (EPSaO) foram submetidos à análise de confiabilidade. $\mathrm{O}$ método estatístico empregado foi o coeficiente Alfa $(\alpha)$ de Cronbach, o qual trata-se de uma média de todos os coeficientes de variabilidade que resultam das diferentes maneiras de dividir meio a meio o conjunto de avaliadores. Assim o Alfa ( $\alpha$ ) de Cronbach, é uma propriedade inerente do padrão de resposta da população estudada, não uma característica da escala por si só, ou seja, o valor de Alfa sofre mudanças segundo a população na qual se aplica a escala (STREINER, 2003).

Observando o nível de confiabilidade dos questionários obtido a partir do valor do coeficiente ( $\alpha$ de Cronbach), o qual resultou em 0,95 para EST e 0,96 para a EPSaO, sendo esses resultados considerados altos, proporcionado a veracidade interna dos construtos mensurados.

Realizou-se também a análise do comportamento dos dados por meio dos testes estatísticos Kolmogorov-Smirnov e Shapiro-Wilk, verificou-se que as variáveis em ambas as escalas não apresentam uma distribuição normal. Perante essa condição, os testes estatísticos utilizados foram os não-paramétricos.

\subsubsection{Avaliação da satisfação no trabalho}

A Escala de Satisfação no Trabalho - EST é uma medida multidimensional construída e validada com o objetivo de avaliar o grau de contentamento do trabalhador diante de cinco dimensões, sendo: (i) satisfação com os colegas de trabalho; (ii) satisfação com o salário, (iii) satisfação com a chefia; (iv) satisfação com a natureza do trabalho; e (v) satisfação com as promoções (SIQUEIRA, 2008).

\subsubsection{Satisfação com os colegas}

Essa dimensão analisa a satisfação no trabalho considerando fatores como, contentamento com a colaboração, a amizade, a confiança e o relacionamento mantido com os colegas de trabalho. A Tabela 02 apresenta os resultados para essa dimensão.

TABELA 02 - DIMENSÃO - SATISFAÇÃO COM COLEGAS

\begin{tabular}{l|c|c}
\hline Grau de percepção & Qtde. & $\%$ \\
\hline Insatisfeito (entre 1 e 3,9) & 03 & 3,3 \\
\hline Indiferente (entre 4 e 4,9) & 07 & 7,5 \\
\hline Satisfeito (entre 5 e 7) & 83 & 89,2 \\
\hline Total & 93 & 100 \\
\hline
\end{tabular}

FONTE: Dados da pesquisa (2019).

Conforme apresenta-se na Tabela 02, o grau de satisfação com os colegas, $89,2 \%$ dos participantes indicaram que estão satisfeitos com seus colegas, $7,5 \%$ se sentem indiferentes e, outros 3,3\% estão insatisfeitos com os mesmos.

Moscovici (2002), explica que o interpessoal tem grande importância dentro das organizações, pois garante um ambiente agradável tanto para o grupo que compõem quanto para a organização. O suporte proporcionado pelos colegas de 
trabalho forma uma rede social que possibilita ao trabalhador experiências positivas no trabalho e gera condições para o reconhecimento de suas competências e contribuições para a organização (TAMAYO et al., 2004).

Esse resultado também pode ser analisado com base em Seidel e Trócoli (2006) e Tamayo et al. (2004), os quais apontam que o suporte social oferece uma proteção ao indivíduo frente a potencialização de estressores do dia a dia laboral, pois ao mesmo tempo que influencia emoções positivas, favorece a solução de demandas que estão além da capacidade individual do trabalhador.

\subsubsection{Satisfação com o salário}

A satisfação com o salário segundo Siqueira (2008), tem como finalidade avaliar o contentamento com o que recebe com salário se comparado com o quanto o indivíduo trabalha, com sua capacidade profissional, com o custo de vida e com os esforços feitos na realização do trabalho. Os resultados apresentam-se na Tabela 03.

TABELA 03 - DIMENSÃO - SATISFAÇÃO COM SALÁRIO

\begin{tabular}{l|c|c}
\hline Grau de percepção & Qtde. & $\%$ \\
\hline Insatisfeito (entre 1 e 3,9) & 11 & 11,8 \\
\hline Indiferente (entre 4 e 4,9) & 14 & 15,1 \\
\hline Satisfeito (entre 5 e 7) & 68 & 73,1 \\
\hline Total & 93 & 100 \\
\hline
\end{tabular}

FONTE: Dados da pesquisa (2019).

A dimensão satisfação com o salário apresenta um grau de satisfação alto, onde $73,1 \%$ dos respondentes estão satisfeitos com o salário que ganham, comparando com o quanto trabalham e seus esforços feitos na realização do trabalho, $15,1 \%$ indicaram ser indiferentes quanto ao valor que recebem como salário, e 11,8\% estão insatisfeitos, pois acreditam que ganham menos do que deveriam ganhar pelo tanto que trabalham.

De acordo com Oliveira e Medeiros (2011), o salário e os benefícios são meios que os trabalhadores possuem para conseguir seus bens fundamentais, satisfazendo suas necessidades. Entretanto, esse benefício não pode ser cancelado, pois isso pode causar uma atitude de inversão a satisfação, ou seja, a insatisfação. Os resultados para esta dimensão sugerem que a organização deve estabelecer ações gerenciais para melhorar o grau de satisfação de seus colaboradores em relação as políticas de remuneração.

\subsubsection{Satisfação com a chefia}

Satisfação com a chefia tem como objetivo avaliar o grau de contentamento com a organização e capacidade profissional do chefe, com o seu interesse pelo trabalho dos subordinados e entendimento entre eles. A Tabela 04 apresenta os resultados para essa dimensão.

Nesta dimensão verifica-se que o grau de satisfação relacionado com a chefia da organização aponta uma porcentagem alta entre os respondentes, 92,5\% consideram que possuem bons chefes, já $7,5 \%$ são indiferentes com a capacidade profissional do seu chefe, e 0,0\%, ou seja, nenhum responde está insatisfeito com a 
maneira como seus chefes realizam seus trabalhos ou com o interesse pelo trabalho dos subordinados e o entendimento entre eles.

TABELA 04 - DIMENSÃO - SATISFAÇÃO COM CHEFIA

\begin{tabular}{l|c|c}
\hline Grau de percepção & Qtde. & $\%$ \\
\hline Insatisfeito (entre 1 e 3,9) & 0 & 0,0 \\
\hline Indiferente (entre 4 e 4,9) & 7 & 7,5 \\
\hline Satisfeito (entre 5 e 7) & 86 & 92,5 \\
\hline Total & 93 & 100 \\
\hline
\end{tabular}

FONTE: Dados da pesquisa (2019).

Robbins, Judge e Sobral (2010), destacam que os líderes têm a possibilidade de influenciar os trabalhadores para alcançar determinado objetivo. Os chefes devem saber conduzir e motivar seus subordinados, pois isso pode refletir positivamente ou negativamente nos índices das organizações. Além de ser também, o chefe exemplo que o empregado tende a seguir na organização, e quando este não está de acordo com os princípios básicos e éticos o funcionário não se sente propicio a desenvolver sua atividade com maior satisfação. Um ambiente com comunicação aberta com a chefia é fonte de satisfação no trabalho, sendo que um dos itens importantes que elevam a altos índices de satisfação é ter uma chefia compreensiva e responsável.

\subsubsection{Satisfação com a natureza do trabalho}

A satisfação com a natureza do trabalho analisou aspectos relacionados ao contentamento com o interesse despertados pelas tarefas, com a capacidade de elas absorverem o trabalhador e com as variáveis das mesmas. Os resultados para essa dimensão estão apresentados na Tabela 05.

TABELA 05 - DIMENSÃO - SATISFAÇÃO COM A NATUREZA DO TRABALHO

\begin{tabular}{l|c|c}
\hline Grau de percepção & Qtde. & $\%$ \\
\hline Insatisfeito (entre 1 e 3,9) & 1 & 1,1 \\
\hline Indiferente (entre 4 e 4,9) & 6 & 6,4 \\
\hline Satisfeito (entre 5 e 7) & 86 & 92,5 \\
\hline Total & 93 & 100 \\
\hline
\end{tabular}

FONTE: Dados da pesquisa (2019).

Diante dos resultados da Tabela 05 verifica-se que $92,5 \%$ dos respondentes sente-se satisfeitos em relação as tarefas que desempenham na organização, já $6,4 \%$ responderam se sentir indiferentes em relação ao interesse que que suas tarefas the oferecem e apenas $1,1 \%$ se sente insatisfeito com 0 trabalho que desempenha e com a variedade das mesmas.

Para Robbins, Judge e Sobral (2010), trabalho que seja interessante e que forneça aos funcionários treinamento, variedades, independência e controle, satisfazem a maioria dos colaboradores. Diante disso, quanto mais a organização proporcionar formas de crescimento e desenvolvimento, mais o empregado tende a ficar satisfeito com seu trabalho. 
Satisfação no trabalho diz respeito a uma atividade laboral que seja pessoalmente e simultaneamente interessante e significativa, capaz de conduzir ao sucesso e produzir um sentimento de realização, criar possibilidade de uso de habilidades e capacidades, propiciar o crescimento pessoal e profissional; envolver certa variedade de tarefas, exigir responsabilidade e apresentar determinado grau de autonomia na tomada de decisões, clareza de papéis (MARTINEZ; PARAGUAY, 2003).

\subsubsection{Satisfação com as promoções}

Nesta dimensão segundo Siqueira (2008), avalia-se o contentamento com o número de vezes que já recebeu promoções, com as garantias oferecidas a quem é promovido, com a maneira de a empresa realizar promoções e com o tempo de espera pela promoção. A Tabela 06 apresenta os dados para essa dimensão.

TABELA 06 - DIMENSÃO - SATISFAÇÃO COM PROMOÇÕES

\begin{tabular}{l|c|c}
\hline Grau de percepção & Qtde. & $\%$ \\
\hline Insatisfeito (entre 1 e 3,9) & 12 & 12,9 \\
\hline Indiferente (entre 4 e 4,9) & 11 & 11,8 \\
\hline Satisfeito (entre 5 e 7) & 70 & 75,3 \\
\hline Total & 93 & 100 \\
\hline
\end{tabular}

FONTE: Dados da pesquisa (2019).

Conforme verifica-se na Tabela 06, a dimensão satisfação com promoções aponta que $75,3 \%$ dos respondentes estão satisfeitos com o número de vezes que já receberam promoções na empresa ou com a maneira que ela realiza as mesmas, outros $12,9 \%$ se sentem insatisfeitos com as promoções oferecidas pela organização, e 11,8\% não concordam e nem discordam em relação a essa dimensão.

Segundo Bergamini (2008), as organizações que proporcionam o atendimento dos interesses e aspirações pessoais, também melhoram sua produtividade devido a forma que consideram cada indivíduo que compõem a organização. Desta forma as promoções proporcionadas aos trabalhadores têm grande importância quando corrobora com a satisfação em trabalhar.

A satisfação com as promoções inclui a presença de oportunidades, justiça e clareza tanto no sistema de promoções quanto no plano de cargos e salários. Também podendo ser acrescentado o reconhecimento, isto é, a necessidade humana de receber créditos pelas realizações, elogios, desde um anúncio público na empresa até comentários informais (MARTINEZ; PARAGUAY, 2003). Os achados sugerem que a organização em estudo deve rever suas estratégias e planos de promoção de seus colaboradores.

Considerando os resultados a partir das dimensões da EST verifica-se que em todas as dimensões: satisfação com os colegas, satisfação com o salário, satisfação com a chefia, satisfação com a natureza do trabalho e satisfação com promoções os resultados sugerem a um bom grau de satisfação com o trabalho a partir da percepção dos colaboradores da organização. No entanto, identifica-se que há pesquisados insatisfeitos com os salários que recebem, bem como com o sistema de promoção utilizado pela organização. 


\subsubsection{Avaliação da saúde organizacional}

A escala de Percepção de Saúde Organizacional - EPSaO foi construída e validada com 0 propósito de verificar a percepção dos empregados a respeito da saúde da organização diante de dois fatores, sendo: (i) integração de pessoas e equipes e (ii) flexibilidade e adaptabilidade a demandas externas (GOMIDE JR; FERNANDES, 2008).

\subsubsection{Integração de pessoas e equipes}

A integração de pessoas e equipes avalia a percepção do trabalhador quanto às crenças do empregado de que a organização é capaz de estimular o compartilhamento de objetivos organizacionais e a integração de seus membros às equipes de trabalho. A Tabela 07 apresenta os resultados pare esse fator.

TABELA 07 - INTEGRAÇÃO DE PESSOAS E EQUIPES

\begin{tabular}{l|c|c}
\hline Média do fator & Qtde. & Percentual \\
\hline Média fatorial entre 1 e 2,9 & 4 & $4,3 \%$ \\
\hline Média fatorial entre 3 e 3,9 & 37 & $39,8 \%$ \\
\hline Média fatorial entre 4 e 5 & 52 & $55,9 \%$ \\
\hline Total & 93 & $100 \%$ \\
\hline
\end{tabular}

Fonte: Dados da pesquisa (2019).

Diante dos resultados da Tabela 07 percebe-se que a média fatorial entre 4 e 5 é a que apresentou maior representatividade na escala utilizada, na qual 55,9\% dos respondentes do estudo indicaram que percebem que a organização onde trabalham é capaz de estimular o compartilhamento dos objetivos organizacionais e a integração de seus membros às suas equipes de trabalho. Os outros $39,8 \%$ dos respondentes apresentam dúvida quanto a esse fator, e apenas uma minoria representada por $4,3 \%$ tem a percepção negativa quanto a essa capacidade da organização.

Para Fordyce e Weil (1971), os sinais de que uma organização é saudável está no compartilhamento dos objetivos da organização, na existência de um ambiente onde as pessoas se sintam à vontade para falar sobre os problemas diretamente com os responsáveis, na ênfase em resoluções práticas aos problemas, na determinação de que as decisões são tomadas segundo a competência, a responsabilidade e a organização do trabalho e não segundo ao nível hierárquico, no espirito de equipe que é desenvolvido nos planejamentos e soluções de problemas, na importância dada às opiniões dos funcionários independentemente do nível que ocupem, na consideração das necessidades individuais quando se precisa tomar alguma decisão e na colaboração espontânea das pessoas, principalmente em momentos de crise.

\subsubsection{Flexibilidade e adaptação de demanda externas}

O fator flexibilidade e adaptabilidade a demandas externas, busca avaliar a percepção do trabalhador quanto às crenças do empregado de que a organização possui políticas e procedimentos de trabalho flexíveis e voltados para a adaptação 
da organização às demandas do ambiente externo. Os resultados são apresentados na Tabela 08.

TABELA 08 - FLEXIBILIDADE E ADAPTAÇÃO AS DEMANDAS EXTERNAS

\begin{tabular}{l|c|c}
\hline Média do fator & Qtde. & Percentual \\
\hline Média fatorial entre 1 e 2,9 & 2 & $2,2 \%$ \\
\hline Média fatorial entre 3 e 3,9 & 29 & $31,2 \%$ \\
\hline Média fatorial entre 4 e 5 & 62 & $66,7 \%$ \\
\hline Total & 93 & $100 \%$ \\
\hline
\end{tabular}

Fonte: Dados da pesquisa (2019).

Conforme verifica-se na Tabela 08, 66,7\% dos participantes da pesquisa demostram ter certeza que a organização demostra flexibilidade nas suas políticas e procedimentos quando da necessidade de adaptação às demandas do ambiente externo. Já 31,2\% demostraram ter dúvidas a respeito desse fator e apenas 2,2\% indicaram que está flexibilidade não é perceptível na organização.

Pferffer e Salancick (1978) consideram que as organizações têm que se relacionar com o ambiente, para importar recursos e obter o suporte legitimador que mantém os processos internos, as organizações adquirem efetividade possuindo interdependência entre os recursos e respondendo às necessidades dos grupos que controlam esses recursos.

As organizações têm ciclos de vida semelhantes ao do ser humano, por esse motivo a sobrevivência da instituição depende da forma de contato apropriado que faz com o ambiente externo ao qual está vinculada. Assim, uma organização efetiva é aquela capaz de fazer adaptações em meio às mudanças do ambiente, sendo flexíveis em suas políticas e ações quando viável (REDDIN, 1970).

Considerando os resultados apresentados para os dois fatores que compõem a EPSaO, no qual $55,9 \%$ dos respondentes da pesquisa indicam que percebem que existe a capacidade de estimular o compartilhamento dos objetivos organizacionais a integração de seus membros às suas equipes de trabalho, e outros $66,7 \%$ da mesma forma percebem que há flexibilidade nas políticas e procedimentos organizacionais na adaptação às demandas do ambiente externo. Estes resultados sugerem que a organização em estudo apresenta um nível de saúde organizacional satisfatório de acordo com a percepção de seus colaboradores.

\subsection{RESULTADOS ALÉM DAS ESCALAS EST E EPSAO}

Com objetivo de verificar o relacionamento entre as dimensões utilizadas por este estudo, as quais buscou analisar o grau de satisfação no ambiente de trabalho (EST) e a saúde organizacional (EPSaO), foi realizada a correlação entre os dois construtos.

De acordo com Field (2009) a análise de correlação compreende em verificar a intensidade da relação por meio do valor do Coeficiente $(r)$, sugerindo a interpretação da seguinte maneira: de 0,10 a 0,29 ou de $-0,10$ a -0,29 (intensidade pequena), de 0,30 a 0,49 ou de -0,30 a -0,49 (intensidade média), e de 0,50 a 1,0 ou de $-0,50$ a $-1,0$ (intensidade alta). A intensidade da relação independe do sinal. $O$ sinal indica apenas a direção da relação. 
Segundo Field (2009), levando o coeficiente de correlação ao quadrado (r2), se tem o coeficiente de determinação $\left(R^{2}\right)$, o qual é uma medida da quantidade de variação em uma variável que é explicada pela outra. A Tabela 9 apresenta os resultados da correlação de Spearman entre a EST e EPSaO.

TABELA 09 - CORRELAÇÃO ENTRE OS CONSTRUTOS EPSAO E EST

\begin{tabular}{ll|l|c|c}
\hline & & EPSaO & EST \\
\hline \multirow{2}{*}{ Rô de Spearman } & \multirow{2}{*}{ EPSaO } & Coeficiente de Correlação & 1,000 &, 783 \\
\cline { 3 - 5 } & & Sig. (2 extremidades) & $\cdot$ &, 000 \\
\cline { 2 - 5 } & EST & Coeficiente de Correlação &, 783 & 1,000 \\
\cline { 2 - 5 } & Sig. (2 extremidades) &, 000 & $\cdot$ \\
\hline
\end{tabular}

**. A correlação é significativa no nível 0,01 (2 extremidades).

b. De Lista $\mathrm{N}=93$

Fonte: Output SPSS (2019).

Analisando a correlação entre as escalas (EST e EPSaO) pode-se identificar que há uma correlação positiva e intensidade alta em $(0,783)$. A correlação entre os construtos apresentou o valor $p<0,05$, ou seja, apresentou significância estatística dentro dos parâmetros aceitáveis para a área das ciências sociais aplicadas. Ampliando a análise utilizando o coeficiente de determinação $\left(R^{2}\right)$ conforme propõe Field (2009), $61,3 \%$ da variação do grau de satisfação no trabalho é explicada pela variação da saúde organizacional. A disposição da correlação de Spearman pode ser observada no Gráfico 02.

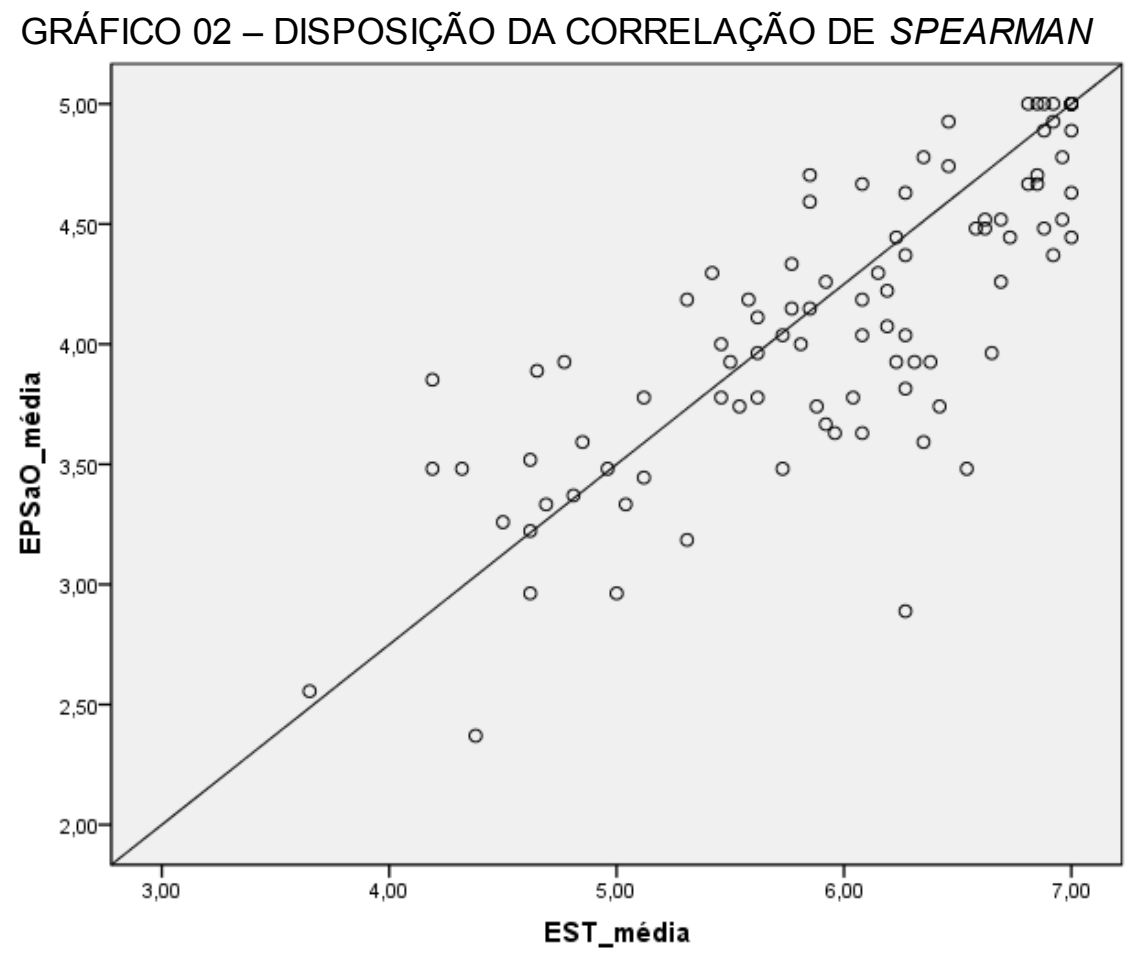

Fonte: Output SPSS (2019).

\section{CONSIDERAÇÕES FINAIS}

As organizações têm cada vez mais se preocupado com o bem-estar dos colaboradores, e desta forma a satisfação no trabalho e saúde organizacional são 
dois temas que tem grande relevância para esse novo olhar das organizações para o fator humano. Desta forma, o presente trabalho buscou analisar a satisfação no trabalho e a saúde organizacional de acordo com a percepção dos colaboradores, para que possa proporcionar um melhor entendimento por parte da organização, compreendendo e avaliando as necessidades a partir da opinião dos colaboradores.

Considerando os resultados a partir das dimensões da EST verifica-se que em todas as dimensões: satisfação com os colegas; satisfação com o salário; satisfação com a chefia; satisfação com a natureza do trabalho; e satisfação com promoções, os resultados sugerem a um bom grau de satisfação com o trabalho a partir da percepção dos colaboradores. No entanto, identifica-se que uma minoria dos pesquisados estão insatisfeitos com os salários que recebem, bem como com o sistema de promoção praticado pela organização.

Os resultados apresentados para os dois fatores que compõem a EPSaO, aponta-se que a organização estudada apresenta nível satisfatório, de acordo com a percepção dos colaboradores, pois os resultados indicam que 55,9\% dos respondentes percebem que existe a capacidade de estimular o compartilhamento dos objetivos organizacionais e a integração de seus membros às suas equipes de trabalho, e $66,7 \%$ da mesma forma percebem que há flexibilidade nas políticas e procedimentos organizacionais na adaptação às demandas do ambiente externo.

Buscando ampliar as análises, outros resultados foram obtidos a partir dos construtos utilizados na avaliação de satisfação no trabalho e saúde organizacional indicada pelos funcionários. Os resultados sugerem correlação positiva de intensidade alta em $(0,783)$ com significância estatística $(p<0,05)$ entre os construtos, indicando que $61,3 \%$ da variação do grau de satisfação no trabalho é explicada pela variação da saúde organizacional.

Através destes resultados, está pesquisa pode contribuir para ampliar o conhecimento sobre o tema no campo da pesquisa organizacional, pois possibilitaram entendimento sobre os construtos que compõem a satisfação no ambiente de trabalho e saúde organizacional, proporcionando aos gestores da organização mais conhecimento e reflexão sobre os aspectos estudados, e assim podendo promover ações na área de gestão de pessoas.

Como limitação do estudo ressalta-se sua realização em um corte transversal, sendo que estudos longitudinais podem resultar em novas contribuições tanto teórica como empírica. Ademais, ressalta-se que os resultados obtidos são válidos apenas para a amostra estudada em uma única organização, limitando-as possíveis generalizações.

\section{REFERÊNCIAS}

BENNIS, W.G. Changing organizations: essays on the development and evolution of human organization. New York: MacGraw- Hill, 1966.

BERGAMINI, C. W. Motivação nas organizações. 5. ed. São Paulo: Atlas, 2008.

BEZERRA, M. V. V. Nível da saúde organizacional: o caso da $\mathrm{J} V$ Cunha distribuidora de alimentos. 2017. 44f. Monografia (Trabalho de Conclusão de Curso) - Universidade Federal do Rio Grande do Norte, Centro de Ensino Superior do 


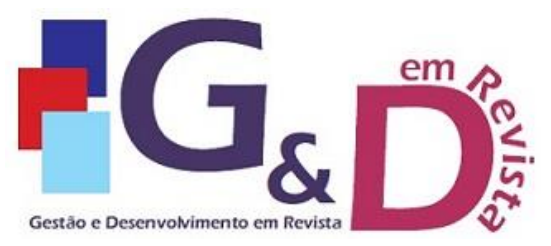

Gestão e Desenvolvimento em Revista V. 6, N. 1, jan-jun/2020, p. 28-45.

ISSN online: $2446-8738$

Artigo recebido em: $26 / 03 / 2020$

Artigo aprovado em: 10/06/2020

Seridó Departamento de Ciências Sociais e Humanas Curso de Administração, Currais Novos, 2017.

CHIZOTTI, A. Pesquisas em ciências humanas e sociais. 2. ed. São Paulo: Cortez, 1995.

FIELD. A. Descobrindo a estatística usando SPSS. 2.ed. Porto Alegre: artemed, 2009.

FREIRE, R. S. Comprometimento organizacional e satisfação no trabalho: uma análise da gestão de recursos humanos. Adm. Diálogo: São Paulo, 1999.

FORDYCE, J. K.; WEIL, R. Managing with people: a managers handbook methods. Reading: Addison Wesley, 1971.

GOMIDE JR. S.; MOURA, O.I.; CUNHA, W.B.; SOUSA, W.M.V. Explorando o conceito de saúde organizacional: construção e validação de um instrumento de medida para o ambiente brasileiro. In: Reunião Anual de Psicologia, 29., 1999, Campinas. Resumos de comunicações científicas, Campinas: SBP, 1999. p.43.

GOMIDE JR., S.; FERNANDES, M. N. Saúde organizacional. In: SIQUEIRA, M. M. $M$. et. al. Medidas do comportamento organizacional: ferramentas de diagnóstico e de gestão. Porto Alegre: Artmed, 2008. Cap. 17, p. 275-282.

GONÇALVES. H, de A. Manual de metodologia da pesquisa científica. São Paulo: Avercamp, 2005.

HAIR, J.; BLACK, W. C.; BABIN, B. B.; ANDERSON, R. E.; TATHAM, R. L. Fundamentos de métodos de pesquisa em administração. Porto Alegre: Bookman, 2005.

HERNANDEZ, J. D. Impactos da percepção de saúde organizacional no bemestar no trabalho. 2007. 84 f. Dissertação (Mestrado), Universidade Federal de Uberlândia, Programa de Pós-Graduação em Psicologia, Uberlândia, 2007.

JAFFE, D.T. The healthy company: Research paradigms for personal and organizational health. In Sauter, S. L. Murphy, L. R. (Eds) Organizational risk factors for job stress. Washington DC: APA, 1995.

KATZ, D; KAHN, R. L. The social psychology of organizations. New York: Wiley, 1966.

MALHOTRA, N. K. Pesquisa de marketing: uma orientação aplicada. 6. ed. Porto Alegre: Bookman, 2012.

MARTINS. G, de A; THEÓPHILO. C, R. Metodologia da investigação científica para ciências sociais aplicadas. 2. ed. São Paulo: Atlas, 2009. 


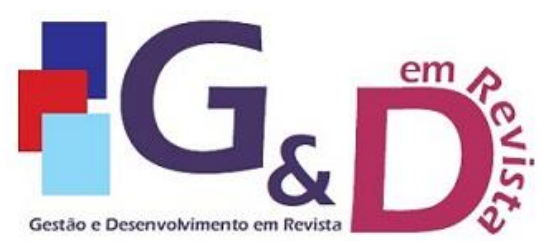

Gestão e Desenvolvimento em Revista V. 6, N. 1, jan-jun/2020, p. 28-45.

ISSN online: $2446-8738$

Artigo recebido em: $26 / 03 / 2020$

Artigo aprovado em: 10/06/2020

MARTINEZ, M. C.; PARAGUAY, A. I. B. Satisfação e saúde no trabalho: aspectos conceituais e metodológicos. Cadernos de psicologia social do trabalho, São Paulo, v. 6, p. 79-99, 2003.

MCSHANE, S. L. GLINOW, M. A. V. Comportamento organizacional. Porto Alegre: AMGH, 2013.

MOSCOVICI, F. Desenvolvimento interpessoal: treinamento em grupo. 12. ed. Rio de Janeiro: José Olympio, 2002.

NEWSTROM, J. W. Comportamento organizacional: o comportamento humano no trabalho. São Paulo: McGraw-Hill, 2008.

OLIVEIRA, J. A; MEDEIROS, $M$ da $P$. Gestão de pessoas no setor público. Florianópolis: Departamento de Ciências da Administração / UFSC; Florianópolis: CAPES: UAB, 2011.

PFEFFER, J.; SALANCIK, G. The external control of organizations: a resource dependence perspective. New York: Harper \& Row, 1978.

ROBBINS, S. P.; JUDGE, T. A.; SOBRAL, F. Comportamento organizacional: teoria e prática no contexto brasileiro. 14. ed. São Paulo: Person, 2010.

REDDIN, W. J. Effectiveness managerial. McGraw: Book Company, 1970.

SCHEIN, E.H. Organizational psychology. Foundations of Modern Psychology series. Englewood Cliffs, NJ: Prentice-Hall, 1965.

SEIDL, E. M. F.; TRÓCOLLI, B. T. Desenvolvimento de escala para avaliação do suporte social em HIV/aids. Psicologia - Teoria e Pesquisa, v. 22, n. 3, p. 317-326, set./dez. 2006.

SIQUEIRA. M, M, M. Medidas do comportamento organizacional: ferramentas de diagnóstico e de gestão. Porto Alegre: Artmed, 2008.

SILVA, R. B. Para uma análise da satisfação com o trabalho: sociologia, problemas e práticas. CIES-ISCTE / CELTA, 1998.

STREINER, D. L. Being inconsistent about consistency: when coefficient alpha does and doesn't matter. Journal of Personality Assessment. v. 80, p. 217-222. 2003.

TAMAYO, A.; LIMA, D.; SILVA, A.V. Clima organizacional e estresse no trabalho. In: TAMAYO, A. Cultura e saúde nas organizações. Porto Alegre: Artmed, 2004. P.77-101.

VERGARA, Sylvia Constant. Projetos e relatórios de pesquisa em administração. 15. ed. São Paulo: Atlas, 2014. 